\title{
Nimuendajú às voltas com a história
}

\author{
Marta Rosa Amoroso \\ Professora do Departamento de Antropologia - USP \\ Pesquisadora do CEBRAP
}

\begin{abstract}
Resumo: Em 2000 foi editado em Portugal o livro "Cartas do Sertão de Curt Nimuendajú para Carlos Estevão de Oliveira". Textos do etnólogo inéditos em português continuam, por sua vez, despontando em revistas especializadas, atestando o interesse dessas etnografias realizadas na primeira metade do século $\mathrm{XX}$, a partir de trabalho de campo pioneiro.Este artigo considera que as cartas padrão de relato diverso daquele que caracteriza as monografias etnográficas descritivas, gênero no qual Nimuendajú se consagrou - acrescentam novo aspecto a sua obra.
\end{abstract}

Palavras-chave: História dos índios, americanismo tropical, Arqueologia.

Curt Nimuendajú nasceu alemão em 1883 e morreu brasileiro em 1945 em uma aldeia tikuna no Alto Solimões. Naturalizara-se brasileiro em 1922 com o nome que recebera dos Nandeva-Guarani em 1906, nome que significa "fazer moradia" (Nimuendajú, 1987: 32). Com o nome guarani, ganhava uma causa. Em "Nimongaraí" deixava registradas as impressões da cerimônia de seu batismo indígena, realizada em uma fria madrugada de dezembro e firmava um compromisso: "quando o sol (...) nasceu atrás da floresta, iluminava um novo companheiro da tribo dos Guaranis que, apesar da sua pele clara, compartilhou com eles lealmente no curso de dois anos a miséria de um povo agonizante." (Nimuendajú, 2001a: 149). De fato dedicou sua vida à militância indigenista e à pesquisa etnológica, atividades praticadas de maneira intensa. Conviveu com um grande número de sociedades indígenas de 
todas as regiões do Brasil, ao mesmo tempo em que manteve diálogo com o americanismo que se ensaiava timidamente nos museus de etnologia da Europa e dos Estados Unidos.

Nos últimos anos Nimuendajú voltou à cena editorial, com a publicação de uma tese que destaca a vida e obra do etnólogo (Grupioni, 1998). Sua correspondência foi publicada em parte pelo Museu Nacional de Etnologia de Lisboa, que apresenta em edição ilustrada (Nimuendaju, 2000) a coleção de cartas que Nimuendajú endereçou a seu amigo Carlos Estevão de Oliveira, na época diretor do Museu Paraense Emílio Goeldi. O último número da revista Mana traz dois de seus textos inéditos em português(2001 a e 2001b), a Revista de Antropologia, por sua vez, publica no presente volume "Excursões pela Amazônia", texto originalmente publicado em alemão ${ }^{1}$.

O interesse redobrado pela obra do etnólogo, parte dela ainda inédita em português e dispersa em instituições nacionais e estrangeiras, dá mostras que os artefatos de inspiração culturalista que soube esculpir como ninguém no início do século, a partir de experiência de campo pioneira, ganham com o tempo maior valor ${ }^{2}$. Sua correspondência se acrescenta a este acervo como peça de valor inestimável para os interessados na história dos índios, do indigenismo no Brasil e dos estudos americanistas.

Nimuendajú produziu valiosos registros etnográficos da maioria dos grupos indígenas que visitou, como "As lendas da criação e da destruição do mundo como fundamentos da religião dos Apapocuva-Guarani", monografia considerada uma das obras-primas da etnologia brasileira (Viveiros de Castro, 1987). Seu empenho em etnografar a complexa organização social dos grupos Jê $\hat{\mathrm{e}}^{3}$ contribuiu, por sua vez, para que a moderna reflexão etnológica de David Maybury-Lewis e Claude LéviStrauss pudessem avançar sobre bases seguras nas décadas de 1950 e 1960. Nimuendajú registrou de forma meticulosa as instituições ameríndias e o resultado obtido, como ele mesmo tinha consciência, na maioria das vezes superou o conhecimento de sua época: "em matéria de americanística" - comentava em sua visita ao Museu de Etnologia 
de Gotemburgo, na Suécia em 1934 - "eles é que podiam aprender de mim, esta é a dura verdade” (2000: 213).

Utilizava uma metodologia só mais tarde consagrada pela antropologia, que conjugava controle da língua nativa, longa permanência com os índios e imersão no modo de vida das comunidades indígenas. "Consciência empírica" e "limpidez etnográfica" são atributos reconhecidos na obra de Nimuendajú até por autores que, como Florestan Fernandes (1975: 119), cobraram do etnólogo alemão maior elaboração interpretativa do material apresentado. Deslocava-se sozinho para as aldeias, evitando tanto quanto possível a companhia de outros pesquisadores ou aparatos que considerava incompatíveis com um tipo de investigação que dependia exclusivamente da aceitação pelo grupo visitado, da generosidade da hospedagem e, acima de tudo, da extrema paciência dos índios para ensinar.

\section{Cartas do Sertão}

Nimuendajú inventariou instituições nativas ainda quando delas restava apenas a frágil memória de uma anciã. Em visita ao Posto Paraguaçu, na Bahia, em 1938, conheceu Dona Jacynta Grayira - uma das últimas falantes da língua -, que ouvia com dificuldades, mal compreendendo as questões formuladas pelo etnólogo sobre o parentesco. Dona Jacynta interessou-se, entretanto, pelo teatro de bonecos que Nimuendajú improvisou com caixas de filmes e garrafas vazias, dispostos em uma mesa para representar os parentes falecidos e o grau de parentesco entre eles. Ao final de um mês de árduo trabalho o etnólogo contava com o inventário dos termos de parentesco na língua Camacã, além de lendas e um vocabulário da língua. Dona Jacynta e seus numerosos parentes lucraram com a reforma de sua casinha e com mantimentos providenciados pelo etnólogo durante sua estadia (Grupioni, 1998: 191-94). Neste e em outros casos são as cartas de Nimuendajú que revelam métodos e técnicas de etnografia, uma arte do relacionamento humano que o etnólogo soube tão bem cultivar. 
Sua correspondência acrescenta, assim, novo aspecto a uma já consagrada obra etnológica e indigenista. Suas cartas são verdadeiras crônicas das mudanças que se processavam entre as sociedades indígenas do sertão do Brasil. Nelas, Nimuendajú mostra-se às voltas com a história, a sua própria história de imigrante alemão que aporta no Brasil. O tema da história e das mudanças vertiginosas do período do entreguerras aparecem, por exemplo, quando o etnólogo retorna à Alemanha em 1934 e não reconhece sua terra natal sob a roupagem opressiva, monótona e sombria da propaganda nazista. Ironicamente, a condição de alemão levará Nimuendajú a ser tomado mais de uma vez como espião a serviço da Alemanha na Amazônia, tanto por índios como pelos "civilizados". Tais desconfianças infundadas levaram Nimuendajú a desistir de pesquisar os Sateré-Maué, povo que o recebeu com hostilidade na década de 1920, "insuflados contra espiões alemães" (Nimuendajú, 2000). Na década de 1940 a xenofobia partia do Conselho de Fiscalização das Expedições Artísticas e Científicas no Brasil (Grupioni, 1998: 20343) e repercutiu no contexto local das aldeias Tikuna, onde o etnólogo foi encontrado morto, num episódio envolto em mistério.

\section{Indigenismo}

As cartas revelam principalmente as histórias dos índios, muitas das quais Nimuendajú figurou como protagonista em graus variáveis de engajamento. Nas primeiras décadas do século XX o Estado brasileiro inaugurava uma nova forma de atuação junto às populações indígenas. Criado o Serviço de Proteção aos Índios(SPI) em 1910, impunha-se uma orientação leiga e de inspiração positivista no trato com essas sociedades. Foi um período de profundas transformações da política indigenista e de criação de novos instrumentos de mediação entre o Estado e as populações indígenas, diverso das premissas da "Catequese e Civilização" adotadas pelo governo do Império, que havia encarregado as missões católicas da questão indígena. Nimuendajú foi crítico mordaz 
das premissas do programa civilizador conduzido pelo Estado e a Igreja católica junto aos índios.

O etnólogo ingressou no Serviço de Proteção aos Índios em 1910, instituição que propunha, entre outras inovações, o respeito à religiosidade, à língua e a toda forma de expressão das tradições nativas. Foi demitido em 1915, por denúncias de espionagem, voltando a atuar no período de 1921-1923, quando foi novamente demitido (Grupioni, 1998: 177). Manteve, entretanto, ao longo da vida contato com alguns de seus funcionários e com a instituição, para a qual prestava serviços esporádicos. Arrojado e firme nas decisões, Nimuendajú compunha o grupo de indigenistas que a "inspetoria" contava para implementar o novo programa, juntamente com Horta Barbosa, Bento Pereira Lemos e José Maria da Gama Malcher. O grupo trabalhou na "pacificação" de populações indígenas, na transferência de aldeias, operacionalizou intervenções a favor dos índios nos conflitos por questões territoriais com os "cristãos". Também participou na reformulação da política indigenista leiga do Estado republicano.

A correspondência com Carlos Estevão de Oliveira se dá no momento em que Nimuendajú, aos 43 anos de idade, vinte dos quais passados entre os índios, abandonava definitivamente o Serviço de Proteção aos Índios e optava por se dedicar aos estudos etnológicos. Nas Cartas do Sertão, escritas do Araguaia, do Tocantins, das aldeias xerente, canela, mawé, ecoam a um só tempo a denúncia do extermínio físico dos índios que se processava cotidianamente no interior do Brasil e o sentido do exercício da ciência antropológica na primeira metade do século XX: o salvamento das "preciosidades indígenas".

\section{"Preciosidades indígenas"}

A expressão foi utilizada pelo etnólogo ao se referir à cerâmica arqueológica de diferentes padrões encontrada na superfície das ruas de Santarém ("esta mina inesgotável de cerâmica"), em Alter do Chão, 
no Amapá, ou na Ilha Caviana na foz do Amazonas, evidência da diversidade das culturas pré-coloniais que outrora habitaram a região amazônica. Aplicava-se, da mesma forma, a um certo tipo de antropologia que se exercia por meio da coleta sistemática da cultura material e do registro lingüístico das sociedades indígenas consideradas na época fadadas a desaparecer ou a se "aculturar".

A montagem de coleções de arqueologia ou de artefatos indígenas correspondeu a uma atividade significativa da etnologia praticada no século XIX até as primeiras décadas do século $\mathrm{XX}^{4} \mathrm{e}$, ainda que não de forma exclusiva, Nimuendajú também se dedicou à tarefa. Entre 1922 e 1927 o trabalho do etnólogo foi em grande parte orientado pelo interesse dos museus europeus em adquirir coleções de arqueologia e de artefatos indígenas.

"Excursões pela Amazônia" nos remete ao contexto específico das investigações conduzidas pelo Museu de Gotemburgo, na Suécia, e ao mapeamento das áreas culturais que caracterizaram a ocupação précolonial da América. Assim, a primeira excursão de Nimuendajú à Ilha de Marajó, em 1922, buscava identificar os montículos (mounds) e cemitérios de urnas, evidências arqueológicas que na maioria dos casos estão associadas a enterramentos humanos. Em Santarém observou à superfície da terra "estratos culturais extraordinariamente interessantes e ricos sobre os quais a atual cidade está edificada" e assim construiu a hipótese que ali seria o ponto de difusão da cultura tapajó. Pesquisas posteriores em Alter do Chão, Óbidos e Amapá buscaram delinear os limites geográficos da cultura Santarém. Os diferentes tipos de cerâmica encontrados na região documentavam, por sua vez, a complexidade da história do povoamento da foz do Amazonas.

As excursões ao rio Madeira e ao Oiapoque tiveram da mesma forma objetivos arqueológicos, que não se cumpriram muitas vezes devido à exploração comercial dos terrenos, outras pela total descaracterização das evidências, com o desbarrancamento das margens dos rios. Nimuendajú entrava em contato, entretanto, com as populações indígenas vivas, e 
Revista de Antropologia, São Paulo, USP, 2001, v. 44 nº 2.

começava a considerar que talvez fosse esta a tarefa mais imediata a ser cumprida pela etnologia.

A passagem para uma segunda fase dos trabalhos do etnólogo, marcada por novos interesses, paradigmas científicos e parcerias, se dá ao final da década de 1920, estando o pesquisador ainda envolvido com obrigações assumidas com museus europeus de montagem e remessa de coleções de etnologia.

Neste sentido, Cartas do Sertão cumpre a função de ser um guia das coleções arqueológicas e da cultura material das sociedades indígenas do Brasil reunidas por Nimuendajú, depositadas até 1927 nos museus de etnologia da Europa e a partir da década de 1930 nos EUA e nos museus brasileiros. Aqui, a orientação segura é garantida pelas notas bibliográficas de Thekla Hartmann, que buscam localizar as coleções dos artefatos ameríndios, assim como identificar a rede de cientistas suecos, alemães, holandeses e norte-americanos que estiveram no Brasil na primeira metade do século XX estudando os índios, entre os quais se destacam os nomes de Alfred Metraux, Nils Erland Nordenskiöld (1877-1932), Fritz Krauze (1811-1963), Theodor Koch-Grünberg (18721924), Felix Speiser (1880-1949) ${ }^{5}$.

Em uma verdadeira corrida contra o tempo no salvamento das culturas nativas, percorria-se as terras indígenas em busca de sociedades dignas de serem etnografadas. Estabelecendo um gradiente dos estágios de contato da população indígena, Nimuendajú considerava, por exemplo, a Aldeia do Ponto dos índios Canela uma verdadeira "mina etnográfica, onde se poderia estudar instituições sociais e religiosas dos Timbira em toda a sua extensão" (Nimuendajú, 2000: 139). Dispunha na outra extremidade do gradiente do contato os Mura, os Sateré-Maué, os Mundurucu, os índios do rio Negro, os Palikur do Oiapoque, populações indígenas em estado avançado de "aculturação" e, portanto, quase sem valor para a pesquisa etnográfica da época.

Nimuendajú alertava para a necessidade da etnologia dedicar-se de forma sistemática aos Timbira e a outros povos Jê do Brasil Central e 
desvendar os intrincados aspectos de sua organização social. "A corrida de toras" (2001b: 151-94) é uma bem-sucedida demonstração que fornece as peculiaridades dos Jê e o início de uma segunda etapa de trabalhos do etnólogo, marcada pela parceria com Robert Lowie, etnólogo radicado nos EUA, ligado ao Departamento de Antropologia da Universidade de Berkeley, Califórnia. Nimuendajú realizava por meio da etnografia desta prova de atletismo - usualmente interpretada pelos regionais como uma dança ou prova de casamento - uma explanação sobre a organização sociocerimonial que orienta as regras daquelas sociedades, que envolve além das metades, as classes de idade, os ciclos de festas, os "grupos de pintura". Roberto DaMatta (1992) chama a atenção para a qualidade dos trabalhos de Nimuendajú inaugurados nesta fase Jê, fato que atribui à parceria com Lowie, que formulava de Berkeley questões para serem respondidas em campo por Nimuendajú, dotando a investigação de um suporte teórico ausente em outros dos seus trabalhos.

\section{"Aculturados"}

O interesse científico de Nimuendajú declinava visivelmente diante das populações indígenas consideradas em grau avançado de "aculturação". Se os Palikur, apesar de "horrivelmente creolizados", portavam ainda uma interessante cultura material - o que possibilitava a realização de coleções museológicas - quase nada havia a dizer dos Mura do rio Madeira: "Hoje estes restos dos Mura são etnograficamente quase sem valor". Nimuendajú percorreu as 25 aldeias mura em 1926, calculou sua população em 1.150 pessoas, mas constatava "que as tradições estão esquecidas, a língua quase extinta". "Talvez se tivesse chegado trinta anos antes..." (2000: 94). No rio Negro, que esteve a serviço do SPI em 1927, observava também "que a decadência da cultura indígena é espantosa; todos para isso se coligam" (: 111). No caso do rio Negro, identificava os padres salesianos como os principais agentes das mudanças, denunciando 
Revista de Antropologia, São Paulo, USP, 2001, v. 44 nº 2.

que os religiosos "apresentavam suas medidas como vontade do Governo" (2000: 94). Entre os Guajajara em 1929, surpreende-se ao ver "as índias com cabelos à la garçonne dançar ao toque da harmônica - e ainda convidaram-me para fazer parte" (: 135).

Nimuendajú chegou a cunhar um neologismo - Schlammbugrismo (sendo schlam $=$ lama) - para se referir ao estado de aviltamento físico e moral dos índios Kaingang e Xokleng do sul do país e das populações indígenas em geral, quando em contato com a sociedade nacional. Buscando reagir contra um estado geral de desânimo que reconhecia nos colegas indigenistas e nele próprio, recomendava que se lançasse mão do estudo das organizações sociais indígenas, atividade que considerava um verdadeiro elixir para reanimar os índios a cultivarem suas tradições. Em sua opinião, a simples presença de alguém interessado nas tradições indígenas operava na maioria das vezes uma reversão no processo gradativo de aculturação. Relata que estimulados pela presença do etnólogo, os índios do rio Negro realizaram - à revelia dos missionários católicos - o que julgava ser um último ritual Jurupari. Constatava algo semelhante entre os Xerente, os Apinayé e os Ticuna: seu interesse pela morfologia social, pelas cosmologias, sua presença atuante nos conflitos com fazendeiros e patrões na condição de representante do Estado faziam ressurgir das cinzas rituais e instituições nativas aparentemente esquecidas.

Assim, a narrativa que acompanhamos por meio da correspondência de Nimuendajú constitui um padrão de relato diverso daquele que caracteriza as monografias etnográficas descritivas, gênero no qual Nimuendajú se consagrará. As cartas trazem uma reflexão pessoalíssima sobre, afinal, de que matéria se constituía a alteridade indígena e o quanto esta estava ameaçada pelas vicissitudes do contato com os brancos. Por vezes esta reflexão "de dentro" da cena humana que estava sendo narrada supera os vaticínios que pairavam sobre o futuro dos índios. Escrevendo de uma aldeia xerente, Nimuendajú mostra que a história podia pregar suas peças na antropologia de viés culturalista 
praticada na época. O etnólogo registrava em 1937 sobre os Xerente que (2000: 263) "seu ideal, ser tão refinado e velhaco como os cristãos, eles realizam plenamente" e completava: "no entanto, vi sobressair, em pé ainda, naquele montão de escombros e lixos, alguns esteios de antigo edifício: por exemplo, até hoje não conseguiram se livrar da lei da exogamia das moities". Os Xerente conservavam-se índios e cônscios do valor da tradição, ainda que "cauterizados com todos os ácidos da civilização". Tal conservadorismo xerente amparava-se no caráter profundamente místico e religioso que se notava em alguns indivíduos. Constatava, afinal, que os índios podiam realizar de forma peculiar a incorporação dos valores da civilização cristã.

Nimuendajú, no entanto, compartilhava com o indigenismo de sua época a posição que os índios deveriam ser protegidos contra as ameaças que pairavam sobre eles, vindas das esferas regionais. $O$ recurso que o poder central lançava mão para garantir tal proteção era ainda o princípio jurídico da "Tutela dos Índios", herança do governo do Império, mantida pelo Serviço de Proteção aos Índios (e também pela Funai até há pouco tempo), que considerava a população indígena incapaz de se autogovernar. Assim, a antropologia do início do século XX fazia vistas grossas ao regime da tutela dos índios, que incapacitava legalmente o índio. Talvez por considerar tal constrangimento conveniente às bravatas quixotescas contra as mudanças culturais e em prol da manutenção intacta das "preciosidades indígenas". Incorriam, sem dúvida, em excesso de zelo.

Em uma das cartas que escreve dos Xerente, Nimuendajú conta que recebera o nome de Seliemtói, o mesmo que davam a D. Pedro II "que ainda hoje (1930) vive na memória deles como a personificação da bondade e sabedoria" (2000: 159). A memória do Imperador foi também registrada entre os Sateré-Mawé (Figueroa, 2000) e entre os Krahó (Melatti, 1970; Carneiro da Cunha, 1986), populações indígenas que, como os Xerente, viveram no século XIX a experiência dos aldeamentos indígenas implantados por D. Pedro II. A presença do etnólogo alemão, articulando um discurso favorável aos índios, reavivava naquelas 
sociedades a memória de jornadas passadas. Ali, quase um século antes, estiveram outros europeus interessados nos índios, os frades capuchinhos italianos que falavam em nome do Imperador D. Pedro II, figura tornada lendária naqueles sertões indígenas.

Entre os Tikuna em 1941, no centro de um movimento messiânico em gestão nos igarapés, Nimuendajú percebe estar sendo confundido com algum ser místico, alguém que podia trazer notícias do herói cultural Dyói. Evento estrangeiro aportando nas sociedades indígenas, ele mesmo seria traduzido de múltiplas formas, todas elas ancoradas na cosmologia e no repertório mítico dos povos visitados. Engajado no seio das atribulações das sociedades indígenas, Nimuendajú subestimou, talvez, a capacidade dos índios lidarem com as mudanças. Elas, na maioria das vezes, não conduziam pela via única que dava acesso à "civilização cristã". Ao contrário, diante de seus olhos delineavam-se novas histórias das populações indígenas que a antropologia se dedica atualmente a interpretar. Para o trabalho das novas gerações de etnólogos americanistas, é sempre bem-vinda a reflexão de Curt Nimuendajú.

\section{Notas}

1 Original em alemão "Streifzuege in Amazonien”, publicado em Etholo-Anzeiger (Stuttgart, 1929-1932, vol. II: 90-7).

2 Ver Grupioni (1998) tanto para bibliografia, inventário dos manuscritos e da correspondência de Curt Nimuendajú, como para a localização das instituições que têm sob a guarda seu acervo.

3 Três monografias marcam a fase Jê na obra de Nimuendajú: "The Apinaye", 1939; “The Sherente”, 1942 e "The Eastern Timbira”, 1946.

4 Sobre a predominância alemã na etnologia indígena nesta fase, ver Melatti (1983).

5 Caberia uma observação aos editores da correspondência de Nimuendajú. O leitor se ressente da ausência de índices temáticos (onomástico, das etnias, 
geográfico), imprescindíveis em obras do gênero. As anotações da professora Thekla Hartmann, por sua vez, dispostas no final do volume em corpo de letra pequeníssimo, receberam um tratamento gráfico que não condiz com a importância da contribuição que prestam ao volume.

\section{Bibliografia}

\section{CARNEIRO DA CUNHA, M.}

1986 "Lógica do mito e da ação. O movimento messiânico canela de 1963", in Antropologia do Brasil. Mito, História, Etnicidade, São Paulo, Brasiliense.

DAMATTA, R.

"Relativizando o Interpretativismo", in CORRÊA, Mariza \& LARAIA, Roque (orgs.), Roberto Cardoso de Oliveira: homenagem, Campinas, UNICAMP.

FERNANDES, F.

1975 A investigação etnológica no Brasil e outros ensaios, Petrópolis, Vozes.

FIGUEROA, A.

2000

“O Imperador dos Sateré-Mawe”, in Ricardo, Carlos Alberto (org.), Povos indigenas no Brasil 1996-2000, São Paulo, Instituto Socioambiental (ISA).

GRUPIONI, L. D. B.

1998 Colecõoes e expedições vigiadas. Os etnólogos no Conselho de Fiscalização das Expedições Artísticas e Científicas no Brasil, São Paulo, Hucitec/ANPOCS.

NIMUENDAJÚ, C.

2000 Cartas do Sertão de Curt Nimuendajú para Carlos Estevão de Oliveira, Apresentação e Notas Thekla de Hartmann, Lisboa, Museu Nacional de Etnologia/ Assírio \& Alvim, Coleção Coisas de Índios.

2001 "Nimongarai", Mana, vol. 7(2): 143-49.

2001 “A corrida de toras dos Timbira", Mana, vol. 7(2): 151-94. 
Revista de Antropologia, São Paulo, USP, 2001, v. 44 nº 2.

MELATTI, J. C.

1970 O sistema social Khahó, São Paulo, tese, Departamento da Antropologia, USP.

1983 "A Antropologia no Brasil: um roteiro". Trabalhos em Ciências Sociais, Série Antropologia, n. 38, Universidade de Brasília.

VIVEIROS DE CASTRO, E.

1987 "Nimuendajú e os Guarani”, in Nimuendajú, Curt. As lendas da criação e destruição do mundo como fundamentos da religião dos Apapocuva-Guarani, São Paulo, Hucitec. 


\begin{abstract}
In 2000, a book entitled "Cartas do Sertão de Curt Nimuendajú para Carlos Estevão de Oliveira" ("Letters from the Backlands by Curt Nimuendajú to Carlos Estevão de Oliveira") was published in Portugal. The appearance of Nimuendajú's previously unpublished writings in Portuguese attests to the interest which continues to be shown in regard to this early twentieth century ethnographer and his pioneer fieldwork. By focusing on the ethnographer's letters, a literary genre which is distinct from the descriptive ethnographies for which he is better known, this article examines a new dimension of Nimuendajú's work.
\end{abstract}

KEY WORDS: Native American History, Tropical Americanism, archeology.

Recebido em dezembro de 2001. 